Outlines-2001-1.qxd 19-06-01 13:31 Side 5

\title{
Voices in History
}

\begin{abstract}
Summary
Experiences of "hearing voices" nowadays usually count as verbal hallucinations and they indicate serious mental illness. Some are first rank symptoms of schizophrenia, and the mass media, at least in Britain, tend to present them as antecedents of impulsive violence. They are, however, also found in other psychiatric conditions and epidemiological surveys reveal that even individuals with no need of psychiatric help can hear voices, sometimes following bereavement or abuse, but sometimes for no discernible reason. So do these experiences necessarily mean insanity and violence, and must they be thought of as pathogenic hallucinations; or are there other ways to understand them and live with them, and with what consequences?

One way to make our thinking more flexible is to turn to history. We find that hearing voices was always an enigmatic experience, and the people who had it were rare. The gallery of voice hearers is, though, distinguished and it includes Galilei, Bunyan and St Teresa. Socrates heard a daemon who guided his actions, but in his time this did not signify madness, nor was it described as a hallucination. Yet in 19th century French psychological medicine the daemon became a hallucination and Socrates was retrospectively diagnosed as mentally ill. This paper examines the controversies which surrounded the experience at different points in history as well as the practice of retrospective psychiatry. The conclusion reached on the basis of the historical materials is that the experience and the ontological status it is ascribed are not trans-cultural or trans-historic but situated both in history and in the contemporary conflicts.
\end{abstract}

\section{Introduction}

Tf you enquire in Britain today what "hearing voices" means, you will probably be told these experiences are hallucinations, which indicate madness. Your informants might quote from national newspapers, which tend to associate hearing voices with an out of control violence (Leudar and Thomas, 2000, Ch. 8). In psychiatry, verbal hallucinations are regarded typically as symptoms of serious mental illness. They are reported in $60 \%$ to $75 \%$ of people with schizophrenia (see Wing, Cooper and Sartorius, 1974; Slade and Bentall, 1988), but they also occur in other psychiatric conditions, such as severe depressive disorders, bipolar disorders, dissociative disorders and post-bereavement states (e.g. Goodwin and Jamison, 1990; Ross, Norton and Wozney; 1989; Rees, 1971; Grimby, 1993) and following sexual abuse (Ensink, 1993; Greenfield et al, 1994). The usual explanation in cognitive psychology is that verbal hallucinations result from reality testing errors - something subjective is mistaken for something which is objective and public - a vivid memory, for example, may be taken for a perception. Furthermore, in psychiatry verbal hallucinations have been long considered to be an important source of delusions and in fact the 
different' to the concepts, unlike those of the natural sciences (Hacking, 1997). ${ }^{1}$ So are the experiences we are considering here "indifferent" to whether they are "hallucinations", "visions" or whatever else? Are they biological phenomena, which are indifferent to culture and the language used to speak of them? These are empirical questions, but before turning that way, let us forestall a possible mutual misunderstanding by stating two maxims we are guided by. One is that experiences always happen under a description, they are never, so to speak "raw". The other is that the influence of concepts on experiences should not be formulated in a cognitive manner (as happens for instance in linguistic determinism and relativism), but as mediated by the work of concepts in practices. If concepts operated solely as cognitive mental representations, how could they materially affect their referents? Concepts are social tools which resource practices in which experiences are formed and situated, including the experiences of mental distress. The lesson is to remember Austin, and to pay attention to the pragmatics of concepts not just to their syntax and semantics.

It would be possible to demonstrate this approach using contemporary materials and we have done so elsewhere (e.g. Leudar, Thomas, et al, 1997; Davies, Thomas and Leudar, 1999). Here the focus will be on history. We will examine the practice of retrospective psychiatry, point out some of its problems and provide a somewhat different way to examine historical texts and consider implications for psychology. from the object to the concept. In his $R e$ writing the Soul, Ian Hacking recently provided some nice instances of how new concepts, such as "sexual abuse" and "multiple personality", resourced new ways of being "mentally ill" (Hacking, 1995). He termed this "looping effects" and subsequently limited the scope of the looping: the phenomena of social sciences (their objects) are not 'in-

\footnotetext{
1 As we have argued elsewhere, Hacking in effect rediscovered a traditional distinction between the natural and the social sciences, and a traditional explanation for the 'undeveloped' state of the latter: that the phenomena of natural science remain invariant across changing theories, whilst those of the social sciences may respond to, and be changed by, the succeeding theories - see Leudar and Sharrock (1999).
} 
Outlines-2001-1.qxd 19-06-01 13:31 Side

OUTLINES • No. $1 \bullet 2001$

\section{Retrospective psychiatry}

$\mathrm{R}$ etrospective psychiatry consists in reading old or very old texts in the light of contemporary concepts. It involves re-writing the past in the light of changing knowledge, and substituting new understandings of experiences and behaviours for the old ones. This makes sense if you hold that psychiatry is a natural science, and your aim is to formulate laws, principles and categories which are valid universally, not just locally. After all, Galileo discovered the moons of Jupiter for all times, not just for the Italy of the renaissance. And John Dalton did not propose atomic theory just for Manchester and just for the 18th century. So "natural" psychiatric categories such as schizophrenia, and concepts such as hallucinations should apply without a problem to other places and times. But do they?

An admittedly somewhat unusual demonstration of the practice of retrospective psychiatry and its problems is to try to read Samuel Beckett's Company as if it were a psychological document.

\section{It starts}

"A voice comes to one in the dark. Imagine. To one on his back in the dark. This he can tell by the pressure on his hind parts and by how the dark changes when he shuts his eyes and again when he opens them again. Only a small part of what is said can be verified. As for example when he hears, You are on your back in the dark. Then he must acknowledge the truth of what is said. But by far the greater part of what is said cannot be verified. As for example when he hears, You first saw the light on such and such a day." (Samuel Beckett, Company, p.1)

The reader turns a professional and asks himself, "Is Beckett talking about hallucinations here?" and starts reading the text as a professional, bearing the concept of verbal hallucination in mind. He continues to read:
"Slowly he entered dark and silence and lay there for so long that with what judgement remained he judged them to be final. Till one day the voice. One day! Till in the end the voice saying, You are on your back in the dark. Those its first words. Long pause for him to believe his ears and then from another quarter the same. Next the vow not to cease till hearing cease. You are on your back in the dark and not till hearing cease will this voice cease." (Samuel Beckett, Company, p. 2223)

He finds that the voice speaks to the hearer about his past, always in the second person singular. It is repetitious, speaking "with only minor variants the same bygones". These characteristics of the voice are much like those many voice hearers report to psychiatrists or to researchers when describing their voices. Other characteristics do not fit easily, for instance:

\footnotetext{
"The voice comes to him now from one quarter and now from another. Now faint from afar and now a murmur in his ear. In the course of a single sentence it may change place and tone. Thus for example clear from above his upturned face, You first saw the light at Easter and now. Then a murmur in his ear, You are on your back in the dark. Or of course vice versa." (Samuel Beckett, Company, p. 19)
}

The question is, is the voice Beckett is referring to a verbal hallucination? If so, was he himself a voice hearer (the book is introduced as an autobiographic piece), and could one go even further and provide Beckett with a retrospective psychiatric diagnosis? - as we have already seen those going through major depressive episodes may indeed hear voices.

But if you read the book this way you will miss the fact that Beckett used the voice as a literary device. The memories of the character are not his own, but narrated to him by the voice. The device sets up the positioning of the reader with respect to the Unnameable and the narrator - the reader also becomes 
Grace abounding has indeed been read psychologically, and by no lesser psychologists than Hippolyt Taine (1877, Book II, ch. 5), Josiah Royce (1894), William James (1902) and Pierre Janet (1903). The diagnoses provided included "hallucinatory delirium" (Taine), "psychopathy" (James) and "obsession and delirium of scruples" (Janet). In their readings, Bunyan's visions became hallucinations or pseudo-hallucinations, and his temptations became "insistent" or "fixed ideas". William James may have rejected "medical materialism" and its explanation of religion in his Varieties of Religious Experience but he also commented

\footnotetext{
"bent as we are on studying religion's existential conditions, we cannot possibly ignore these pathological aspects of the subject. We must describe and name them just as if they occurred in non-religious men." (William James, Varieties of Religious Experience, p. 9)
}

Even though James held that it was misguided to explain religion in dogmatic terms by reference to the mental health of its practitioners he also wrote the following: , which said, Wilt though leave thy and go to Heaven? Or have thy sins, and go to hell? At this I was put to an exceeding maze; wherefore leaving my Cat upon the ground, I looked up to heaven, and was as if I had with the eyes of my understanding, seen the Lord Jesus looking down upon me, as being very hotly displeased with me, and as if he did severely threaten me with some grievous punishment for these, and other my ungodly practices.

I had no sooner thus conceived in my mind, but suddenly this conclusion was fastened on my spirit, (for the former hint did set my sins again before my face) that I had been a great and Grievous Sinner, and that it was now too late for me to look after Heaven, for Christ would not forgive me, nor pardon my transgressions. Then I felt to musing upon this also; and while I was thinking on it, and fearing lest it should be so, I felt my heart sink in despair, concluding it was too late; and therefore I resolved in my mind I would go on in sin. ... I can but be damned; and if it must be so, I had as good be damned for many sins, as to be damned for few." (John Bunyan, Grace Abounding, 1666, pp. 18-19).

\begin{abstract}
"Even more perhaps than other kinds of genius, religious leaders have been subject to abnormal psychical visitations. Invariably they have been creatures of exalted emotional sensibility. Often they have led a discordant inner life, and had melancholy during a part of their career. They have known no measure, been liable to obsessions and fixed ideas; and frequently they have fallen into trances, heard voices, seen visions, and presented all sorts of peculiarities which are ordinarily classed as pathological. Often, moreover, these pathological features in their career have helped to give them their religious authority and influence." (James, 1902, p. 6)
\end{abstract}

John Bunyan, though, did not use the concept of mental illness to understand his suffering. Nor did he use the concept of hallucination to understand his spiritual experiences, even though he sometimes had prob- 
Outlines-2001-1.qxd 19-06-01 13:31 Side

OUTLINES • No. $1 \bullet 2001$

lems in distinguishing them from those more mundane ones, as he indicates:

\begin{abstract}
"Yet still at times, I was helped to believe that it was true manifestations of Grace unto my soul, though I had lost much of the life and savour of it. Now about a week or fortnight after this, I was much followed by this scripture, Simon, Simon, behold, Satan hath desired to have you, Luk. 22. 31. And sometimes it would sound so loud within me, yea, and as it were call so strongly after me, that once above all the rest, I turned my head over my shoulder, thinking verily that some man had behind me called to me, being at a great distance." (John Bunyan, Grace Abounding, 1666)
\end{abstract}

The description under which he has his experience (a "manifestations of Grace") cannot be substituted by another term (hallucination) without losing the sense of it or of his reactions to it. Examining the practice of retrospective psychiatry foregrounds the historical conflict between different versions of the experience and it may help to clarify the extent to which they are constituted by the culture in which they are situated. In particular, we can ask which aspects of hearing voices are invariant, and which are contingent on culture and history. We will next consider in detail the case of Socrates in these terms; what follows is a brief précis of the detailed analysis presented in the Voices of Reason, Voices of Insanity (Leudar and Thomas, 2000).

\section{The case of Socrates}

Socrates is not usually seen as a religious visionary and it does come as a surprise to many who know him just by his popular reputation that he let himself be guided by 'a daemon' which told him what he should not do. This has been well documented by Xenophone, Plato and Socrates, and subsequently commented on by many, including Montaigne, Voltaire, and Nietzsche (see Nehamas, 1998). In the early 19th century, the daemon became "a hallucination" and
Socrates was declared insane on its account. The great Pinel thought that Socrates suffered from catalepsy and Lelut (1836), who dedicated a monograph to the daemon, argued that Socrates was a victim of hallucinations. For Maury (1855) there was no difference between visionaries, ecstatics and madmen. The apparent rationality of visionaries' hallucinations was beside the point - rational hallucinations were still essentially hallucinations, just like those of the inmates of contemporary French asylums. The conclusion was that the great projects of Socrates, Mohamed and Joan of Arc were motivated by hallucinations and monomania. Now this is clearly an extreme position and even the retrospective psychiatrist of Socrates, Lelut had to concede that

"if Pythagoras, Numa, Mahomet etc. were not rogues, but believed in the reality of their visions and revelations, which seems beyond doubt, then these were men of genius and enthusiasm, who had partial, isolated hallucinations in a religious and reforming mode which was fostered by the spirit of their age." (Lelut, 1836, p. 346, cited in James, 1995, p. 91)

But "the spirit of their age" was found wanting:

"This spirit, incapable of understanding such a form of madness, obliged the hallucinator and his witnesses to believe in the reality of his false perceptions of whatever kind." (Lelut, 1836, translated by James, 1995, p. 91)

While Lelut had to admit that the visionaries were not necessarily insane, he deemed the whole age and the culture which spoke and thought differently wanting. Retrospective psychiatry in this mode assumes and demonstrates "progress" (see Schmidt, 2000). This is of course not the only way it uses old texts - Bunyan's spiritual autobiography, for instance, was also used to study the relationship between religion and psychopathology 
(James, 1902) and between genius and insanity (Royce, 1894), see Leudar and Sharock (2001).

You may think that "hallucination" is an concept which has always been to hand, but its psychiatric meaning (which has subsequently become the everyday meaning of the word) was only formulated in the early nineteenth century in England by Sauvages, Sagar, Darwin (see Esquirol, 1845) and in France by Esquirol (1838). Hallucinations then came to be seen as a crucial symptom and source of insanity. There were, however, problems with applying the concept and the French Societé Médico-Psychologique eventually met twice to debate hallucinations (see Brierre de Boismont, 1856). One aim was to see whether one could distinguish normal from pathologic hallucinations, as for instance those in artists and in the insane. The differences between the two were drawn in terms of

- control over the experiences;

- the ability to distinguish "internal perceptions" from perceptions of public external objects, and

- their consistency with reason.

The distinction between normal and abnormal hallucinations in terms of the last consideration was formulated by Brierre de Boismont $(1861 \mathrm{a}, \mathrm{b})$ who proposed that there were two kinds of them: the physiological ones (which were compatible with reason), and the pathological ones (which were not):

\footnotetext{
"But even though their manifestations are the same in the two cases, their character, their logic, their course, their ending establish sharp differences between them.

Physiological hallucination is constantly in touch with the dominant thought, the mother idea, the ideal; it is an echo, an adjunct, a stimulant which decides the success. Whatever its duration, it has the same force at the start and at the end, and it does not trouble the reason.
}

Pathological hallucination, on the other hand, has its origins in diverse causes and mostly false ones; it is almost always associated with delirious conceptions. It invokes most erroneous and contradictory motives. Almost always it is impregnated with childish terrors, or is based on ridiculous exaggerations. It presents remarkable transformations. After time, it causes confusion of ideas and enfeeblement of reason.

These two [kinds of] hallucination have their starting point in mental representations, which exist in all the men, but their different character depends on whether the reason is intact or troubled." (Brierre de Boismont, 1861b, p. 537538, our translation)

So, according to Brierre de Boismont, hallucinations were not in themselves signs of madness, anymore than say are thinking and remembering, even though some people can have bizarre and false memories and some people think delusional thoughts. The madness of some hallucinations was in their involuntariness, delirious content and falsity, in the childish terror of the hallucinator, in other words nothing specific to hallucinating. Brierre de Boismont implied that what is called hallucinating is an ordinary mental function, which can indicate impairment of reason like any other.

But did Socrates really experience verbal hallucinations? Plato, Xenophon and Plutarch refer to his experience (after translation, that is) as "a voice", "a divine sign" "a daemon", "a divine presentiment", "a supernatural experience" but never as a "hallucination". That term, taking the translators' word for it, is simply absent in their narratives. What grounds could we have for saying that the daemon of Socrates was a hallucination? Does it have the correct properties to count as one? Today, as in 19th century France, hallucination is "any percept-like experience which (a) occurs in the absence of an appropriate stimulus, (b) has a full force or impact of the corresponding actual (real) perception and (c) is not amenable to direct 
or voluntary control by the experiencer" (Slade and Bentall, 1988, p. 23). So if the daemon were a hallucination, it should have been an auditory experience with discernible words. It should have been a private experience and in absence of appropriate stimulus. Moreover if the daemon were a pathological hallucination it should have been involuntary and contrary to reason.

There is ample evidence that Socrates indeed experienced his daemon in the auditory modality. Xenophon's Socrates described it as "a divine voice" which "comes to me and communicates what I must do" (Xenophon, SD: 4-12). Plato's Socrates said that he was "subject to a divine or supernatural experience ... It began in my early childhood $-a$ sort of voice which comes to me" (Plato, Apology, 31cd, our emphasis) and "I seemed to hear a voice forbidding me to leave the spot" (Plato, Phaedrus, 242bc, our emphasis). Plutarch had Simmias report in the "daemon of Socrates" that he

\footnotetext{
"had often heard Socrates express the view that men who laid claim to visual communication with Heaven were impostors, while to such as affirmed that they heard a voice he paid close attention and earnestly inquired after the particulars." (Plutarch, OSS, 588c, our emphasis).
}

So Socrates' daemon satisfies the first condition of being an auditory hallucination - it is like hearing somebody. Now, was the experience of the daemon private to Socrates, private like the present day hallucinations of madness are? Or alternatively could Socrates ever hear his daemon together with someone else? None of our sources ever mentions an event such as this. Socrates' actual contact with his daemon is always presented as his own.

\footnotetext{
"Socrates ... happened to be making the ascent toward the Symbolon and the house of Andocides, putting some question to Euthyphron the while and sounding him out playfully. Suddenly he
}

stopped short and fell silent, lost a good time in thought; at last he turned back, taking the way through the street of cabinet makers, and called out to the friends who had already gone onward to return, saying that his sign has come to him." (Plutarch, OSS: 580d-e)

The experience of the daemon involves a withdrawal from social activity, and into Socrates' thoughts. But note that even though it is private in this sense, the experience is still socially situated. Socrates is "lost in thought" with his companions, and he reports the experience to them. The daemon is then a private and yet a social experience. It clearly satisfies the second criterion for being a hallucination: it is a private experience in that it is not co-experienced by Socrates and others Athenians.

Let us next consider whether Socrates had control over the experience and whether he prepared the hallucination in the way a vivid artistic image might follow a period of intense incubation. The answer to both questions is "no" - the demon "came to him" and provided him with wisdom which he himself did not possess. But did Socrates confuse his daemon with ordinary auditory perception? Unlike John Bunyan, he did not.

Thus far then the daemon fits the concept hallucination reasonably well, even though it would be more difficult to say whether it is a pathological or normal hallucination. There is a problem though: does the divine, from which Socrates and his contemporaries thought the voice came, count as an "appropriate stimulus"? Not if you do not believe in daemons. Lelut did not - an appropriate stimulus for hearing someone in France in 1850 s, as it is today, was a person speaking in the vicinity. So we can say that Socrates's daemon was a hallucination. The problem, though, is that Socrates himself could not. Now why is this? He would have to cease to believe in daemons, their wisdom, and their causal powers. Socrates simply could not do 
this and remain who he was - his whole life consisted in seeking wisdom in people, not finding it and concluding that wisdom belongs to gods only. Furthermore, his understanding of the voice as a daemon had many practical consequences. Most people would probably say that hallucinating is an affliction. Plutarch (and the characters in his book), however, concluded that hearing a daemon was a privilege. Why is Socrates granted the privilege? Plutarch wrote:

\footnotetext{
"but whereas some men actually have this sort of apprehension in dreams, hearing better asleep, when the body is quiet and undisturbed, while when they are awake their soul can hear higher powers but faintly, and moreover, as they are overwhelmed by the tumult of their passions and the distractions of their wants, they cannot listen or attend to the message. ... Socrates, on the other hand, had an understanding which, being pure and free from passion, and commingling with the body but little, for necessary ends, was so sensitive and delicate as to respond at once to what reached him." (Plutarch, OSS: 588d-e).
}

So hearing a daemon in Athens indicated that one was gifted rather than insane and the giftedness Plutarch talks about involves being able to resist one's passions. Some men are "overwhelmed by the tumult of their passions and the distractions of their wants" but Socrates is not.

So French medicine looked at hallucinations as signs of unreason, but according to Athenians, Socrates heard the voice of the divine because he was a man of reason; he denied his body, sought wisdom and disdained material possessions. This being so he could do things with his experience which contemporary voice hearers cannot. In other words, we cannot project the concept of hallucination into the past without misunderstanding it.

\section{Controversies about hearing voices}

$\mathrm{S}$ o far I may have been easily taken to be saying that the history of hearing voices moves through a series of consensual descriptions. In Socrates' time it was a sign provided by the divine, but in the nineteenth century it became an auditory hallucination and a symptom of insanity. This is, however, not so. Even in Socrates times the daemon was a point of controversy. First, whilst his fellow Athenians had no problem accepting that he could be in a privileged contact with the divine, the problem was that the daemon was not one of the locally recognised deities. In fact, one of the charges at Socrates' trial was that he was introducing new deities into Athens and thereby corrupting the youth (see Plato, 1993). By the time of Plutarch (1st century AD) the social controversy was different, as is obvious in the apocryphal story and in the following quotations.

\footnotetext{
"Socrates ... happened to be making the ascent toward the Symbolon and the house of Andocides, putting some question to Euthyphron the while and sounding him out playfully. Suddenly he stopped short and fell silent, lost a good time in thought; at last he turned back, taking the way through the street of cabinet makers, and called out to the friends who had already gone onward to return, saying that his sign has come to him. Most turned back with him, I with the rest, clinging close to Euthyphron; but certain young fellows went straight ahead, imagining that they would discredit Socrates' sign, and drew along Charillus the flute-player, who had also come to Athens with me to visit Cebes. As they were walking along the street of statuaries past the law-courts, they were met by a drove of swine, covered with mud and so numerous that they pressed against one another; and there was nowhere to step aside, the swine ran into some and knocked them down and befouled the rest." (Plutarch, On the Sign of Socrates: 580d-f)
} 
"I have it from one of Megarian school, who has it from Terpsion, that Socrates' sign was a sneeze, his own and others': thus, when another sneezed at his right, whether behind or in front, he proceeded to act, but if at his left, he desisted; while of his own sneezes the one that occurred when he was on the point of acting confirmed him in what he had set out to do, whereas the one occurring after he had already begun checked and prevented his movement." (Plutarch, On the Sign of Socrates: $581 \mathrm{~b})$

The argument is now about whether the daemon was a sign of wisdom and virtuous life or humbug and superstition. For some young Athenians the voices came to stand for superstition and to be contrary to reason.

The general lesson here is that perhaps the best method is not to seek the central tendencies at different points in history, but rather it is to examine what is controversial about voices and how the arguments move on. We shall do this for our second historical case, that of "a retrospective hysteric", St Teresa of Avila. The following text is from her autobiography.

"Like imperfect sleep which, instead of giving more strength to the head, doth but leave it the more exhausted, the result of mere operations of the imagination is but to weaken the soul. Instead of nourishment and energy she reaps only lassitude and disgust: whereas a genuine heavenly vision yields to her a harvest of ineffable spiritual riches, and an admirable renewal of bodily strength. I alleged these reasons to those who so often accused my visions of being the work of the enemy of mankind and the sport of my imagination. ... As for myself, it was impossible to believe that if the demon were its author, he could have used, in order to lose me and lead me to hell, an expedient so contrary to his own interests as that of uprooting my vices, and filling me with masculine courage and other virtues instead, for I saw clearly that a single one of these visions was enough to enrich me with all that wealth.” (Teresa of Avila, Autobiography - cited by William James, 1902, Varieties of Religious Experience, $\mathrm{p}$. 21, my emphasis)
Note the categories she has available for her

"visions". They can be

- mere operations of the imagination, or

- the work of the enemy of mankind, or finally

- genuine heavenly visions.

The text provides not only these categories but it also indicates the procedures she uses to allocate a particular experience to one of them. One consideration is the nature of the content and the consequences of these visions. ${ }^{2}$ Note, for instance, that the imagination enfeebles the soul, while heavenly visions afford spiritual riches and renew bodily strength. These procedures are though not just St Teresa's own personal ones - her autobiography was assessed in her own time by the church and even by the Inquisition. According to Father Bañes, a Dominican friar delegated to censor the book by the Inquisition:

"One thing only there is about the book that may reasonably cause any hesitation till it shall be very carefully examined: it contains many visions and revelations, the matters always to be afraid of, especially in women, who are very ready to believe of them that they come from God and to look at them as proofs of sanctity, though sanctity does not lie in them." (Teresa of Avila, Autobiography, 1911, p. xxvii)

Father Bañes decided that St Teresa was honest in revealing her visions, unlike the deceivers who may lay claims visions to appear pious. This means that hearing voices is now to be mistrusted. The argument is about whether the mere presence of voices indicated piety and holiness. Bañes argued that this is not so but the need to say this implies that some thought so. Another authority, Father

\footnotetext{
2 In this sense her reasoning probably appealed to William James' Pragmatism and perhaps that is why he provides the text in his book.
} 
Juan d'Avila, provided support for this position by arguing that visions are not necessarily given just to those who are virtuous, but rather those in need of spiritual love and help. The main way, however, to assess visions (i.e. are they from the devil, from the divine or mere psychology) though was in terms of their effects and concordance with the religious dogma. In the case of St Teresa, according to the examiner they moved her to love God and despise herself. "I see no reason for condemning them, I incline rather to regard them as good, provided you are careful not to rely altogether on them, especially if they are unusual, or bid you do something out of the way, or are not very plain. In all these and the like cases you must withhold your belief in them, and at once seek for direction." If we compare this controversy with that concerning the daemon of Socrates, in both humbug may be involved, and the categorisation is achieved relative to religious dogma. The crucial difference is that in Socrates' time hearing voices meant wisdom, in the time of St Teresa they may mean exactly the opposite.

One important point is to be stressed about the visions of St Teresa - it is the resonance between social and individual categories. The positions in the social dispute about voices and the categories available to individuals for the experience are broadly the same.

So far the stress has been on categories for the experiences of hearing voices and on the procedures for assigning experiences into them. The context is, however, important and the extent to which they are idiosyncratic rather than shared with others. The following is an excerpt from the memoirs of the perhaps most famous psychiatric patient in history, D.P. Schreber.
"I believe I may say that at that time and at that time only, I saw God's omnipotence in its complete purity. During the night - and as far as I can remember in one single night - the lower God (Ariman) appeared. The radiant picture of his rays became visible to my inner eye, while I was lying in bed not sleeping but awake - that is to say he was reflected on my inner nervous system. Simultaneously I heard his voice; but it was not a soft whisper - as the talk of the voices always was before and after that time - it resounded in a mighty bass as if directly in front of my bedroom windows. The impression was so intense, so that anybody not hardened to terrifying miraculous impressions as I was, would have been shaken to the core. Also what was spoken did not sound friendly by any means: everything seemed calculated to instil fright and terror into me and the word 'wretch' was frequently heard - an expression quite common in the basic language to denote a human being destined to be destroyed by God and to feel God's power and wrath. Yet everything that was spoken was genuine, not phrases learnt by rote as they later were, but the immediate expression of true feeling." (Daniel Schreber, 1903, 124/136).

In formal terms, Schreber's experiences are not that different from those of Socrates or St Teresa. He divides his experiences into those which are ordinary personal ones or ordinary public ones but also those which are supernatural ones, to which only he has access. Schreber had in effect two outsides, only one of which he shared with other people. He himself accepted that his supernatural experiences had a different meaning for himself and the psychiatrists. In this respect his 'reality testing' capacities were intact. So what makes him a madman rather than a visionary like St Teresa and Socrates were? It is not simply that he had visions and heard voices, it was rather that the supernatural world he spoke of was his alone, and unlike the spiritual realm of religious visionaries it was neither shared nor culturally appropriate. 


\section{Implications for contem-} porary research

\section{卫} The core ideas in the contemporary cognitive approach to verbal hallucinations are as follows. Experiences are assigned into two mutually exclusive categories, they are either subjective or public. This assignment is a matter of meta-cognitive inference (e.g. Bentall, 1990), of preconscious inference (e.g. Hoffman, 1986) or of an unconscious neurophysiological process (e.g. Frith, 1992). The criticism which follows from the historical analysis is that it fails to establish participants' own categories and instead it procrastinates experiences into the objective/subjective dualism. Not all voice hearers or even researchers, however, work with this dualism. William James, for instance, argued in his Varieties of Religious Experience that human experience is not limited to what is provided by the five senses - the spiritual world is as real as the material one and experiences can be "public/objective", "private/psychological" or "spiritual". Any reality testing procedure postulated by a researcher, should take the participants' own categorisation into account. The reason is that, as we have seen, otherwise one may conclude that a voice hearer fails at reality testing, when in fact he or she is assigning experiences consistently into her own categories.

One can draw on William James further to formulate an even more basic criticism of cognitive reality testing. The problem is whether reality testing is necessarily a inferential procedure. James (1902) did not just argue for the "reality of the unseen", he also asserted that there is a sense for perceiving it; the "spiritual" can be apprehended directly, rather than just inferred.

"It is as if there were in the human consciousness a sense of reality, a feeling of objective presence, a perception of what we may call 'something there,' more deep and more general than any of the special and particular 'senses' by which the current psychology supposes existent realities to be originally revealed." (James, 1902, p. 58; our emphasis)

What, according to him, was this "sense of reality"? He provided several examples, including the following:

"I lay awake awhile thinking on the previous night's experience, when suddenly I felt something come into the room and stay close to my bed. It remained only a minute or two. I did not recognize it by any ordinary sense and yet there was a horribly unpleasant 'sensation' connected with it. It stirred something more at the roots of my being than any ordinary perception. The feeling had something of the quality of a very large tearing vital pain spreading chiefly over the chest, but within the organism - and yet the feeling was not pain so much as abhorrence. At all events, something was present with me, and I knew its presence far more surely than I have ever known the presence of any fleshly living creature." (James, 1902, p. 59-60, italics in the original)

The "sense" that James documents here is described as follows. It does not come in "any ordinary sense" (it has, for instance, no visual, or auditory characteristics) yet the experience is spatially localised ("it" comes into the room, stays close to the informant's bed and exits through the door). The "presence" is not seen or heard but "felt", with the feeling in this particular case being one of "abhorrence". There is also a distinct bodily element to the experience (it is like "a tearing vital pain spreading chiefly over the chest"). These elements are common to all the relevant examples which James provides. In general, the direct "reality sense" is partly a matter of intense embodied feelings.

Is this "sense of the unseen" relevant to hallucinations or hearing voices? James seems to propose it is: 
"we might suppose the senses to waken our attitudes and conduct as they so habitually do, by first exciting this sense of reality; but anything else, any idea, for example, that might similarly excite it, would have that same prerogative of appearing real which objects of sense normally possess. So far as religious conceptions were able to touch this reality-feeling, they would be believed in spite of criticism, even though they might be so vague and remote as to be almost unimaginable." (James, 1902, p. 59-60, italics in the original)

It seems then that James therefore intended the "sense of reality" to provide ordinary experiences with a sense of reality as well as to identify the spiritual ones. Moreover the sense of reality can establish what otherwise would have been a hallucination, into an experience of a spiritual event and it can do this retrospectively. James quotes his colleague:

\footnotetext{
"It was about September, 1884, when I had the first experience. On the previous night I had had, after getting into bed at my rooms in College, a vivid tactile hallucination of being grasped by the arm, which made me get up and search the room for an intruder; but the sense of presence properly so called came on the next night, after I had got into bed and blown out the candle." (James, 1902, p. 59)
}

Something which starts as a hallucination is retrospectively assigned a spiritual reality on the grounds of the sense of reality. In representational accounts of mind, a discrete experience is a hallucination if it occurs in the absence of an appropriate discrete event in the world. James's account does not work with discrete ideas but with the "stream of consciousness". An experience may not be taken as a hallucination at the time but it may turn out to be one in depending on the experiences which follow.

There are two implications of these considerations for our approach to hearing voices. One is to pay attention to embodied feelings, which may accompany voices, and to establish how the voice hearer uses these on a particular occasion to establish the ontological status of the experience. The other is that reality testing may be extended in time and not just carried out at the time of experience. It may consist in a family of different cognitive procedures, some of which involve direct perceptions, others meta-cognitive inferences, some done in private, others carried out with others.

In general, when studying experiences, one should pay attention to their occasioned and contentious character, and always ask questions such as the following. What controversies does the experience provoke in particular social and historical contexts? What are participants' own categories for their experiences, and what procedures guide their application? How are the versions of the experience made relevant in concrete circumstances, and what determines whether one category is relevant rather than another?

\section{Bibliography}

Barrett, T. R. \& Etheridge, J. B. (1992). Verbal hallucinations in normals: In People who hear voices. Applied Cognitive Psychology, 6, 379-387.

Barrett, T. R. \& Etheridge, J. B. (1993). Verbal hallucinations in normals: II. Self-reported imagery vividness. Personality and Individual Differences, 15, 61-67.

Barrett, T. R. \& Etheridge, J. B. (1994). Verbal hallucinations in normals: III. Dysfunctional personality correlates. Personality and Individual Differences, 16, 57-62.

Beckett, S. (1979). Company. London: Picador.

Bentall, R.P. (1990). The illusion of reality: a review and integration of psychological research on hallucinations. Psychological Bulletin, 107, 82-95.

Brierre de Boismont, A. (1856). Report on two meetings of Société Médico-Psychologique, 29/10/1855 and 26/11/1855. Annales Médico-Psychologiques, 3rd series, 2, 126-140.

Brierre de Boismont, A. (1861a). On hallucinations. A history and Explanation. London: Henry Renshaw. 
Brierre de Boismont, A. (1861b). Des hallucinations historique ou étude medico-psychologique sur les voix et les révélations de Jeanne D'Arc (part 1). Annales médico-psychologiques, 3rd series, 7, 353-376

Bunyan, J. (1666). Grace Abounding to the chief of Sinners. In Stachniewski, J. and Pacheco, A. (Eds.) (1998). John Bunyan. Grace Abounding with other spiritual Autobiographies. Oxford: Oxford University Press. (pp. 1-94).

Davies, P., Thomas, P. and Leudar, I. (1999). The Dialogical Structuring of Verbal Hallucinations. A Single Case Study. British Journal of Medical Psychology, 72, 179-187.

Ensink, B. (1993). Trauma: A study of child abuse and hallucinations. In Romme, M. and Escher, S. (eds.). Accepting Voices. London: MIND publications.

Esquirol, J.E.D. (1838). Des maladies méntales considerées sous les rapports médicaux, hygiénique et médico-legaux. Paris: Baillière.

Esquirol, J.E.D. (1845). Mental Maladies. A Treatise on Insanity. Philadelphia: Lea \& Blanchard.

Frith, C. (1992). The Cognitive Neuropsychology of Schizophrenia. London: Lawrence Erlbaum Associates.

Goodwin, F.K. \& Jamison, K. R. (1990). Manicdepressive illness. Oxford: Oxford University Press.

Greenfield, S.F., Strakowski, S.M., Tohen, M., Batson, S.C. and Kobrener, M.L. (1994) Childhood abuse in first-episode psychosis. British Journal of Psychiatry, 164, 831- 834.

Grimby, A. (1993). Bereavement among elderly people: grief reactions, post-bereavement hallucinations and quality of life. Acta Psychiatrica Scandinavica, 87: 72-80.

Hacking, I. (1995). Rewriting the soul: multiple personality and the sciences of memory. Princeton, New Jersey: Princeton University Press.

Hacking, I. (1997). Taking Bad Argument Seriously. London Review of Books, 21st of August.

Hoffman, R.E. (1986). Verbal hallucinations and language production processes in schizophrenia. Behavioural and Brain Sciences, 9, 503 548.
James, T. (1995). Dream, Creativity and Madness in Nineteen-Century France. Oxford: Clarendon Press.

James, W. (1902). Varieties of Religious Experience. London: Longman, Green and Co.

Janet, P. (1903). Les obsessions et neuroasthenié. Vol. 1. Paris: Ancienne Librarie Germer Bailliere et co.

Lelut, L.F. (1836). Du démon du Socrat. Paris: Trinquart.

Leudar, I., Thomas, P., McNally, D. and Glinski, A. (1997). What voices can do with words: Pragmatics of verbal hallucinations. Psychological Medicine, 27, 885-898.

Leudar, I. and Sharrock, W. (1999). Essay review: Multiplying the multiplicity: Are dissociative identity disorders 'real'? British Journal of Psychology, 90, 451-455.

Leudar, I. and Sharrock, W. (2001). The cases of John Bunyan. Manchester: Manchester University. (Submitted for publication).

Leudar, I. and Thomas, P. (2000). Voices of reason, Voices of Insanity. London: Routledge.

Maury, A. (1855). Les mystiques extatiques et les stigmatisés. Annales médico-psychologiques, 3e serie, 1, 157-176

Nehamas, A. (1998). The Art of Living. Berkeley: The University of California Press.

Pinel, P. (1806). A treatise on Insanity. Sheffield. (Transl. D.D. Davies.)

Plato (1993). Apology. In H. Tarrant (Ed.). Last Days of Socrates. London: Penguin. (pp. 2967).

Plato (1996). Phaedrus. In Hamilton, E. and H. Cairns (Eds.)The Collected Dialogues of Plato (pp. 475-844). Princeton, N.J.: Princeton University Press.

Plutarch (1959). On the sign of Socrates. In (ed.) Plutarch's Moralia, volume 7, London: William Heineman (pp. 362-509).

Romme, M., Honig, A., Noorthoorn, E.O. and Escher, S. (1992). Coping with hearing voices: an emancipatory approach. British Journal of Psychiatry, 161, 99-103.

Ross, C.A. Norton, G.R. and Wozney, K. (1989). Multiple personality disorder. Canadian Journal of Psychiatry, 34, 413-418.

Royce, J. (1894). The case of John Bunyan. Psychological Review, 1, 22-33, 134-151, 230-240. 
Schmidt, L.E. (2000). Hearing Things.Religion, Illusion, and The American Enlightenment. Cambridge, Mass.: Harvard University Press.

Schreber, D.P. (1903/1955). Memoirs of my mental illness. Cambridge, Mass.: Harvard University Press.Sidgewick, H., Johnson, A., Myers, F.W.H. et al (1894). Report on the census of hallucinations. Proceedings of the Society for Psychical Research, 34, 25-394.

Sidgewick, H., Johnson, A., Myers, F.W.H. et al (1894). Report on the census of hallucinations. Proceedings of the Society for Psychical Research, 34, 25-394.

Slade, P. \& Bentall, R. (1988). Sensory Deception: Towards a scientific analysis of hallucinations. London: Croom Helm.

St Teresa of Avila (1911) The autobiography of St Teresa of Avila. The life of St Teresa of Jesus written by herself. Translated by D. Lewis. Rockford, Ill: Tan Books.

Taine, H. (1877). Histoire de la littérature Anglaise. Paris: Hachette et Superscript.

Tien, A.Y. (1991).Distributions of hallucinations in the population. Social Psychiatry and Psychiatric Epidemiology. 26, 287-292.
Wing, J.K., Cooper, J.E. \& Sartorius, N. (1974). The measurement and classification of psychiatric symptoms. Cambridge: Cambridge University Press.

Xenophon (1990). Socrates' Defense. In R. Waterfield (Ed.), Conversations of Socrates. London: Penguin. (pp. 27-49).

\section{Biographical Note}

Ivan Leudar was born in Czechoslovakia but moved to the United Kingdom and studied psychology at Birkbeck College and University College London. He is now a Reader in Psychology at the University of Manchester. His work in psychology is influenced by ethnomethodology and pragmatics. One of his main current interests is how membership categories for people on the margins are produced, maintained and contested in talk and mass media. His book Voices of Reason, Voices of Insanity was published last year by Routledge. 